\title{
Clinical conceptualization of workaholism: A comprehensive model
}

Organizational Psychology Review 2017, Vol. 7(4) 306-329

(C) The Author(s) 2017

Reprints and permission: sagepub.co.uk/journalsPermissions.nav DOI: $10.1177 / 2041386617734299$ journals.sagepub.com/home/opr

(S)AGE

\author{
Yura Loscalzo and Marco Giannini \\ University of Florence, Italy
}

\begin{abstract}
Workaholism is a behavioral addiction that, while widely studied, is still lacking a definition shared by the scientific community. The aim of this theoretical paper is to propose a new model that is at the same time comprehensive and easy to test, with an approach based on a critical analysis of the literature. We give particular attention to reviews of literature and theoretical and empirical papers published since $20 \mathrm{I}$ I, because even the most recent reviews do not fully encompass the last few years. We proposed a comprehensive model, which defines workaholism as a clinical condition that is characterized by both externalizing (i.e., addiction) and internalizing (i.e., obsessive-compulsive) symptoms and by low levels of work engagement; from this there arises the distinction between disengaged and engaged workaholics (i.e., a less impairing subtype of workaholism). Finally, we propose DSM-like criteria for workaholism and a research agenda for future studies.
\end{abstract}

\section{Keywords}

antecedents, externalizing, heavy work investment, internalizing, outcomes, workaholism, work engagement

\section{Introduction}

Workaholism is a term coined more than 40 years ago by Oates (1971) to describe a worker who feels the compulsion to work incessantly, despite negative consequences for his/her health and social functioning. This represents a widespread behavioral addiction. Andreassen, Griffiths, et al. (2014) found a prevalence of $8.3 \%$ in a representative sample of Norwegian adult workers; Sussman, Lisha, and Griffiths (2011) found a prevalence of $10 \%$ in the American adult population. Furthermore, an

Paper received I July 2016; revised version accepted 8 September 2017.

Corresponding author:

Yura Loscalzo, University of Florence, School of Psychology, Department of Health Sciences, Via di San Salvi I2 - Padiglione 26, 50135 Florence, Italy.

Email: yura.loscalzo@gmail.com 
Italian study indicated that work addiction is common in adolescents too, with $7.6 \%$ prevalence (Villella et al., 2011).

In spite of the growing body of literature there is not yet a diagnostic category for workaholism, either in the last edition of the Diagnostic and Statistical Manual of Mental Disorders (DSM-5; American Psychiatric Association [APA], 2013) or in the International Classification of Mental Disorders (ICD10; World Health Organization [WHO], 1992). The DSM-5 (APA, 2013) claims that, with the exception of the gambling disorder, there is currently not sufficient peer-reviewed evidence regarding behavioral addictions, indicating that it is not possible to define them as mental disorders characterized by specific diagnostic criteria and a description of course. Regarding workaholism specifically, this could be due to the lack of a shared definition and operationalization of criteria.

A related issue is that Andreassen, Hetland, and Pallesen (2014) found that three workaholism measures (i.e., the Work Addiction Risk Test [WART], Robinson, 1989; the Dutch Work Addiction Scale [DUWAS], Schaufeli, Shimazu, \& Taris, 2009; the Workaholism Battery [WorkBat], Spence \& Robbins, 1992) do not have convergent validity. In addition, Patel, Bowler, Bowler, and Methe (2012) pointed out in their meta-analysis that the WorkBat and the WART have different correlations with the work criteria they analyzed. Patel et al. (2012) therefore, concluded that there is a need for consistent definition and operationalization of the construct in order to have further scientific progress in this field. Finally, Loscalzo and Giannini (2015) underlined that it seems that researchers are not interested in validating the theoretical models of workaholism proposed thus far, such as the Heavy Work Investment (HWI) model of Snir and Harpaz (2012).

We believe that it is important to develop a parsimonious and testable definition of workaholism in order to encourage its empirical study and validation, and promote cumulative knowledge about this construct. The aim of this paper is to suggest a comprehensive theoretical model, to be considered as an evolving conceptualization. Future research based on this model may indicate which parts should be eliminated and what new components should be added. In order to develop this model, we critically analyzed the past literature from a clinical perspective. We gave particular attention to literature reviews and to theoretical and empirical papers published since 2011, since the latest reviews do not fully cover the last 6 years. We hope that proposing a simple and complete framework for studying workaholism will foster the development of cumulative knowledge of the phenomenon. This could also potentially point in the direction of formal recognition of workaholism as a mental disorder in the next edition of the DSM, clarifying when overworking might be considered as a clinical condition and when it should not. For this reason, we also suggest a proposal for DSM-like criteria for workaholism at the end of the paper.

\section{Overview of previous theories}

There are a number of reviews of the numerous definitions and classifications of workaholism in the literature (Andreassen, 2014; Clark, Michel, Zhdanova, Pui, \& Baltes, 2016; Giannini \& Scabia, 2014; Grebot, 2013; Sussman, 2012). Since the first definition by Oates (1971), who defined workaholism as characterized by an inner compulsion to work and by impairment, many others have been developed. There are different conceptualizations of the number of elements included both in the definitions (from one-dimensional to threedimensional) and in the typology of classifications (ranging from two to five profiles).

With regard to behavior-based definitions of workaholism, Mosier (1983) proposed a onefactor definition, suggesting that the workaholic be defined as someone who works at least 
50 hours a week, while Fassel (1990) pointed to the negative consequences of workaholism, defining it as a progressive and serious disorder characterized by addiction to working. Mudrack and Naughton (2001) proposed instead a twofactor definition: the worker spends a great deal of time and energy in work activities, exceeding what is required, and he/she has the tendency to control and influence others' work. Finally, Schaufeli, Taris, and van Rhenen (2008) defined workaholics as people who work hard and with much more effort than what is requested and expected from them (in line with Mudrack \& Naughton, 2001), with a second behavioral component related to forgetting their other life duties.

There are also more complex definitions, which go beyond observable behaviors and include cognitive aspects. Machlowitz (1980) and Porter (1996) added a cognitive component to the behavioral one: workaholics overwork due to their intrinsic motivation towards work, rather than to a job's requirements. Regarding the behavioral component, Machlowitz (1980) highlighted that the worker works hard, long, and exceeds both a job's prescriptions and others' expectations; while Porter (1996) wrote that the workaholic neglects other important life areas due to overworking. Similarly, Sussman (2012) defined workaholism as a person's being driven to work beyond a job's requirements, as well as showing impairments due to overworking (behavioral components); however, he specified that the worker is driven (i.e., cognitive component), and he pointed out also the person's feeling of lack of control over working (a second cognitive component). In the same vein, Scott, Moore, and Miceli (1997) included most of the previous components (i.e., workaholics devote many hours to work, exceed a job's demands, and dedicate little time to family and other obligations) in their definition. However, they added a cognitive feature: the workaholic thinks persistently about work, even when he/she is not at work. Focusing on cognitive components of workaholism, it is interesting to note that Robinson (1998) proposed that workaholism is an obsessivecompulsive disorder (and not an addiction, as in most of the previous definitions) characterized by overworking and avoidance of other life activities (behavioral component), and whose cognitive features are self-imposed demands and inability to regulate work habits.

In the literature there are also definitions including an affect-related component. Spence and Robbins (1992) introduced the work enjoyment component in their definition, suggesting a three-factor conceptualization of the construct: high involvement in work, inner drive to work, and low enjoyment while working. Recently, Aziz and Zickar (2006) revived this definition, indicating that workaholism is a syndrome in which the worker has high work involvement and drive to work, and low work enjoyment. However, in contrast with both Spence and Robbins (1992) and Aziz and Zickar (2006), Ng, Sorensen, and Feldman (2007) highlighted that workaholics actually enjoy the act of working, as well as devoting long hours to work at the expense of time dedicated to personal life, and being obsessed with working.

In sum, in line with the first definition of Oates (1971), who coined the term workaholism (and defined it similarly to alcoholism), the majority of scholars have defined workaholism as a behavioral addiction that is characterized by working harder and longer than the average worker does. Using clinical psychology terminology, they have conceptualized workaholism as an externalizing condition, namely as a disorder characteristic of people that cope with psychological discomfort by means of behaviors that are visible to others, such as aggressiveness, antisocial behaviors, or addictions. Moreover, there is also some agreement that the condition also includes an inner compulsion towards one's work, a compulsion that is a feature of obsessive-compulsive disorder, although only few scholars define workaholism as an obsessive-compulsive disorder rather than 
as an addiction (e.g., Robinson, 1998). Again using clinical psychology terminology, Robinson (1998) conceptualized workaholism as an internalizing disorder, a term used to refer to people who cope with psychological discomfort by means of inner and covert behaviors, such as rumination, compulsions, or intrusive thoughts. Finally, most of the definitions also highlight the impairment associated with workaholism, such as neglecting other life areas, a feature of both internalizing and externalizing disorders.

A main difference among these definitions relates to the affective component of workaholism. Some authors do not take this dimension into account, focusing only on behavioral and/or cognitive features and on the negative consequences of workaholism. In addition, among the scholars who consider this affective component too, some propose that workaholism is associated with low work enjoyment (Aziz \& Zickar, 2006; Spence \& Robbins, 1992), while others state that it is associated with high work enjoyment ( $\mathrm{Ng}$ et al., 2007). Consistent with this multiplicity of definitions, there are also many instruments used to measure workaholism. Since a shared definition of workaholism is lacking, it is not surprising that psychometric investigation of three workaholism instruments (i.e., WorkBat, WART, and DUWAS) found that they do not show convergent validity (Andreassen, Hetland, et al., 2014) and that the WART and the WorkBat are differently related to various work criteria analyzed (Patel et al., 2012).

\section{Towards a comprehensive definition of workaholism}

Given the numerous definitions of workaholism, some authors have recently tried to arrive at a unique and comprehensive definition of the construct. Grebot (2013), referring to the transactional model of stress (Lazarus \& Folkman, 1984), stated that the analysis of workaholism should consider its professional (e.g., organizational values) and personal (e.g., perfectionism, neuroticism) antecedents, transactions used to cope with stressful situations, such as coping behaviors, and positive and negative outcomes. Thus, she pointed out that workaholism is due to both individual and organizational (i.e., situational) factors. Along the same lines, Griffiths and Karanika-Murray (2012) stated that workaholism, similarly to other addictions, should be explained by referring not only to psychological characteristics, but also to both structural (e.g., manual vs. nonmanual work, direct or indirect financial rewards) and situational (e.g., organizational culture, coworkers relationships) characteristics of the person's work. Finally, Astakhova and Hogue (2014), using the biopsychosocial framework, referred to personal and situational factors, as Grebot (2013) and Griffiths and Karanika-Murray (2012) did, but they also split the personal factor into two distinct aspects, resulting in a total of three mutually influencing factors that fuel workaholism: biology, psychology, and social context.

In contrast, assuming a person-centered view, Snir and Harpaz (2012) introduced the concept of Heavy Work Investment (HWI), which is defined by both the time and effort applied to one's work, intending to define workaholism better. Based on the HWI framework, they stressed that not all heavy workers are workaholics, and they distinguished between situational and dispositional heavy work investors; the workaholic would represent one dispositional subtype, characterized by addiction to work. In line with this model, Astakhova and Hogue (2014) developed a HWI continuum, including workaholic HWI (which is internally driven, in line with the original definition of workaholism proposed by Oates); situational HWI (contextually driven, for example, by salary or organizational values); and, pseudo-HWI (defined as a false type of HWI, where the worker is focused on power rather than on productivity). Hence, they suggested, as Snir and Harpaz (2012) did, that there may be different kinds of hard workers, 
who should be differentiated when studying workaholism.

Moreover, another study reported that workaholics and engaged employees represent, respectively, negative and positive types of HWI, while burned-out employees and relaxed workers are, respectively, the negative and the positive low-work investors (Salanova, Del Líbano, Llorens, \& Schaufeli, 2014). Finally, although Griffiths and Karanika-Murray (2012) did not refer to the HWI model, they proposed conceptualizing workaholism as being part of a low-high work engagement continuum which goes from withdrawal to healthy engagement and, finally, to extreme engagement. Thus, they suggested that workaholism is a form of extreme engagement that should be distinguished from other kinds of high-engaged workers. In summary, we believe that it is important to refer to the HWI model when studying workaholism. This helps in avoiding considering as workaholics those workers that have a different and distinct form of HWI, and thus to provide a better definition of what workaholism is (or what it is not).

In addition, a recent study verified the existence of two different kinds of workaholism, defined as functional (partially satisfied) and dysfunctional (dissatisfied) workaholism on the basis of the workers' evaluations of their quality of life (Malinowska \& Tokarz, 2014). This particular study highlighted the usefulness of distinguishing not only among different kinds of HWI, but also between functional and dysfunctional workaholics. However, in our view, the most intriguing findings are those reported by van Beek, Taris, and Schaufeli (2011). They demonstrated, by means of an empirical study, that by crossing the two different constructs, namely work engagement and workaholism, three types of hard workers emerge: workaholic employees, engaged employees, and engaged workaholics. Moreover, a fourth kind of worker produced by this crossing is the nonworkaholic/nonengaged employee. Thus, they showed, in line with Snir and Harpaz (2012) and Griffiths and KaranikaMurray (2012), that not all hard workers are workaholics. However, while Snir and Harpaz (2012) distinguished between the person who is workaholic (addicted to work) and one who is work-devoted (the employee with a high passion for his work), and Griffiths and KaranikaMurray (2012) considered workaholism as an extreme form of engagement, van Beek et al. (2011) found that in some employees, workaholism and work engagement (i.e., a positive affect towards one's own job) could both be present.

Two other studies deserve mention, since they attempted to define different kinds of HWI and at the same time to study the stability of these patterns. A 2-year longitudinal study (Mäkikangas, Schaufeli, Tolvanen, \& Feldt, 2013) found four work engagement-workaholism types, as well as finding that both work engagement and workaholism are predominantly stable, even though change is possible, both for better but also for worse. In particular, job change had a positive influence on workaholism and work engagement. Innanen, Tolvanen, and Salmela-Aro (2014) also reported temporal stability for the two profiles they found (engaged and exhausted workaholics), but they also noticed that a minority of employees experienced changes.

\section{A new definition}

From the previous review of definitions it is evident that a comprehensive and shared definition of workaholism is still lacking, despite recent proposals of comprehensive theoretical models. For this reason, we are proposing a simple and complete new framework for studying workaholism in order to promote a coherent and unified understanding of the phenomenon, with particular attention to the need for not overpathologizing a common and often positive behavior such as work. More specifically, based on the most recent literature about workaholism, we propose to merge the 
HWI framework (which includes a distinction between different kinds of HWI, helping to define workaholism better as compared to other forms of HWI) with the typology of different kinds of workaholics (i.e., engaged and disengaged or functional and dysfunctional workaholics), while also highlighting the need for studying both personal and situational antecedents and outcomes when analyzing workaholism.

Before explaining the rationale for the main components of our conceptualization of workaholism, we first propose our definition of workaholism: it is a clinical condition characterized by both externalizing (i.e., addiction) and internalizing (i.e., obsessive-compulsive) symptoms, and by low levels of work engagement; from this, the distinction between disengaged and engaged workaholics arises. Hence, we suggest that disengaged workaholics must be distinguished from the other two types of heavy work investors - engaged workaholics and engaged workers. Engaged workaholics display high levels of externalizing and internalizing symptoms, but also high work engagement. Engaged workers show high work engagement and low levels of addiction and obsessive-compulsive symptoms. We also propose that engaged workaholics are not "real" or clinical workaholics because their high engagement protects them against high levels of functional impairment. However, it may still be valuable to use preventive interventions with them in order to avoid a possible progression to the negative (or clinical) type of workaholism.

\section{Workaholism: Both an internalizing and externalizing clinical disorder}

In order to clarify the first part of our definition, we emphasize that we are utilizing clinical psychology terminology. More specifically, externalizing disorders refer, for example, to substance or behavioral addictions, since they are characterized by behaviors that are visible to others. Anxiety disorders and obsessivecompulsive disorder are instead internalizing conditions, since they are characterized by inner and covert behaviors.

Keeping in mind this clinical conceptualization, the first part of our definition conceptualizes workaholism as a clinical disorder characterized by both externalizing (i.e., addiction) and internalizing (i.e., obsessive-compulsive) symptoms. This is in line with a recent paper by Kardefelt-Winther (2015), who suggests that researchers should go beyond a priori assumptions about addiction when studying a potential new behavioral addiction. He believes that studying the problem behavior without confirmatory biases associated with the addiction approach would be useful for identifying its real characteristics.

In almost 50 years of workaholism literature most scholars have referred to Oates's (1971) definition of workaholism as a behavioral addiction, especially in the most recent publications (e.g., Andreassen, Griffiths, Hetland, \& Pallesen, 2012; Griffiths \& Karanika-Murray, 2012). However, a few have proposed to consider it as an obsessive-compulsive disorder (e.g., Robinson, 1998), supporting the possibility that workaholism could be an internalizing disorder instead of an externalizing one. Hence, even if workaholism is not a potential new behavioral addiction (but rather a widely studied clinical disorder), we believe that it is useful to take a step back in its conceptualization and question its internalizing and/or externalizing nature, since there is not yet consensus on this.

It is nevertheless important to establish whether workaholism is best conceived of as an internalizing or an externalizing disorder, as this could tell us in which section of the DSM it should be placed; it could also help in defining which treatment and prevention programs might be better, based on previous studies on internalizing and externalizing disorders. As far 
as we know, there are no empirical studies or theoretical papers in literature addressing these two potential workaholism components simultaneously. However, there are studies of both internalizing and externalizing features associated with workaholism which, taken as a whole, suggest their potential co-occurrence.

With regard to internalizing factors, some studies have found that workaholics are characterized by traits related to the obsessivecompulsive personality, such as perfectionism (e.g., Bovornusvakool, Vodanovich, Ariyabuddhiphongs, \& Ngamake, 2012; Stoeber, Davis, \& Townley, 2013; Tziner \& Tanami, 2013). In addition, there are also studies showing that workaholism generally represents a stable pattern (Innanen et al., 2014; Mäkikangas et al., 2013); this is congruent with the diagnostic criteria for personality disorders (APA, 2013). With particular regard to obsessive-compulsive personality disorder, its diagnostic criteria include some important aspects that have also been found in workaholics: perfectionism, conscientiousness, and excessive dedication to work and productivity at the expense of leisure and friendships. Finally, workaholism seems to be characterized by both an obsession (constantly thinking about work) and a compulsion (working excessively), required for a diagnosis of obsessivecompulsive disorder, a distinct diagnosis from obsessive-compulsive personality disorder.

Others studies instead found externalizing behaviors, such as aggressive behaviors, in workaholics (Balducci, Cecchin, Fraccaroli, \& Schaufeli, 2012) or proposed considering workaholism as an addiction with the same seven core features of the other substancerelated addictions, namely salience, tolerance, mood modification, relapse, withdrawal, conflict, and problems (Griffiths \& KaranikaMurray, 2012). From a clinical point of view, we found theoretical support for the externalizing component of workaholism in the Freudian ego defense mechanism of sublimation, as it views aggressive and sexual energy as channeled into vocational activities, such as hard work (Sommers-Flanagan \& SommersFlanagan, 2004).

Following these considerations, we propose that:

Proposition 1: Workaholism is characterized by both (a) externalizing (or addiction) and (b) internalizing (or obsessive-compulsive) symptoms.

\section{Disengaged and engaged workaholics}

In the second part of our definition, we suggest that (disengaged) workaholism is a three-factor construct, comprising both internalizing and externalizing symptoms (i.e., the two usual components of clinical workaholism symptoms) and low levels of work engagement. Moreover, we believe that based on low or high levels of work engagement, we can differentiate between disengaged and engaged workaholics.

We believe that making this distinction between engaged and disengaged workaholics is very important since it can help prevent overpathologizing working itself, which is a common and often socially valued behavior. This issue has also been recently raised by Billieux, Schimmenti, Khazaal, Maurage, and Heernen (2015), who criticized the current tendency to label virtually all human activities in terms of behavioral addictions and hence as clinical pathologies. Since work is an important daily activity, and given that we should be aware of the negative effects produced by the stigma in organizations that could be associated with a diagnosis of workaholism, we believe that it is important to make a clinical diagnosis of workaholism only when overworking is associated with low work engagement and high impairment, as usually required by the DSM criteria (APA, 2013). In line with this, Bakker, Schaufeli, Leitier, \& Taris (2008) found that workaholics were not engaged in their work.

For this reason, even if work engagement and workaholism symptoms are indeed two different 
Table I. The four kinds of worker based on their level of workaholism and work engagement.

\begin{tabular}{llll}
\hline & & \multicolumn{2}{l}{ Workaholism symptoms (internalizing and externalizing) } \\
\cline { 3 - 4 } & & Low & High \\
\hline Work engagement & Low & Detached worker ** & $\begin{array}{l}\text { Disengaged workaholic* } \\
\text { High }\end{array}$ \\
& Engaged worker & Engaged workaholic \\
\hline
\end{tabular}

Note. *Clinical workaholic; **Not a heavy work investor.

constructs, we think, in line with van Beek et al. (2011), that they have to be considered together and crossed conceptually in order to identify two different kinds of functionally impaired workaholics. Moreover, this crossing of different constructs is justified by the clinical conceptualization of work-related issues that we propose in this paper; in clinical psychology it is common to have different constructs co-occur in the same person at the same time. For example, people often have more than one clinical diagnosis (e.g., social anxiety disorder and phobic disorder, or general anxiety disorder and major depressive disorder).

We suggest that the disengaged workaholic has high levels of obsessive-compulsive and addiction symptoms, but low levels of work engagement. The engaged workaholic (or less impaired type) shows instead high levels of internalizing and externalizing symptoms, but also high levels of work engagement; the latter could act as a protective agent against severe impairment in wellbeing.

More specifically, we suggest that while disengaged and engaged workaholics represent two kinds of heavy work investors, only the disengaged workaholic should be considered the "real" or clinical workaholic. In fact, we have adopted the HWI model (Snir \& Harpaz, 2012) as a general framework for our conceptualization of workaholism; it is the only theoretical model that has some empirical support in the literature (i.e., van Beek et al., 2011). We believe, in accordance with Snir and Harpaz (2012), that not all hard workers are workaholics, and hence that workaholism represents only one of the various forms of HWI. Thus, adopting the HWI model may help better define workaholism, and it could help prevent pathologizing those hard-work behaviors that do not represent workaholism. However, our reference to work engagement contrasts with Snir and Harpaz's (2012) theoretical conceptualization of workaholism as a dispositional subtype characterized by a single dispositional factor (i.e., work addiction) distinct from people who are highly devoted to their work (i.e., with a high passion for the work), since we make reference to two dispositional factors. We define three types of heavy work investors in relation to their levels of workaholism and work engagement (see Table 1): (a) engaged workers, who have high work engagement and do not have workaholism's symptoms; (b) engaged workaholics, who have high levels of both work engagement and workaholism; (c) disengaged workaholics (or the "real" workaholics) who have high level of workaholism and low level of work engagement (see Table 1, which includes the three types of heavy work investors). Based on the levels of workaholism and work engagement, we also propose a fourth kind of worker who however is not a heavy worker investor. This is the detached worker, who is characterized by low levels of both workaholism and work engagement.

It is important to note that engaged workaholics may well benefit from receiving a preventive intervention as well, aimed at preventing the development of disengaged workaholism over time and at favoring their 
Table 2. Comprehensive model: Individual and situational antecedents.

\begin{tabular}{ll}
\hline Individual antecedents* & Personality traits \\
& Perfectionism \\
Individual antecedents ** & Cognitive aspects ${ }^{\#}$ \\
& Psychiatric disorders \\
& Inability to down-regulate negative emotions \\
Situational antecedents* & Motivation \\
Situational antecedents** & Overwork climate in the family ${ }^{\#}$ \\
\hline
\end{tabular}

Note. *Difficult to change; **Easier to change; ${ }^{\#}$ Research areas deserving major study.

evolution into engaged workers. Indeed, even though engaged workaholics are less impaired than disengaged workaholics are, they are still more impaired than engaged workers (van Beek et al., 2011). They may experience high levels of work-family conflict due to their long-term investment in the work domain at the expense of the family domain. In line with this, van Beek et al. (2011) found that engaged workaholic employees spend even more time working than workaholic ones. Consequently, they may be characterized by high levels of family conflict and not be present as parents, with negative consequences for their children's wellbeing. It should also be noted that long working hours have a negative effect on their job performance, which could negatively affect their organization as well (Pencavel, 2014). Moreover, as highlighted by van Beek et al. (2011), even if engaged workaholics have lower levels of burnout than workaholic employees, they experience a higher level of burnout than engaged workers. This means that they may be at risk of developing high levels of burnout in the future. Therefore, engaged workers should be preferred to both engaged and disengaged workaholics, since the positive effects associated with them are higher for both the individual and the organization (i.e., higher personal wellbeing, lower work-family conflict, and higher productivity).

Given these considerations, we suggest that interventions aiming to reduce workaholism are beneficial for both of the two kinds of workaholics. Moreover, it would be interesting to conduct a deeper analysis of engaged workaholism; it could be studied by examining whether the presence of high levels of both work engagement and workaholism are associated with positive effects for the individual and his/her organization in addition to lessening the negative effects of workaholism as previously proposed.

In conclusion, we propose that:

Proposition 2: Workaholism is a three-factor construct, characterized by: (a) internalizing and (b) externalizing symptoms, and by (c) low level of work engagement.

Proposition 3: There are three kinds of heavy work investors: (a) disengaged workaholics (the "true" workaholic); (b) engaged workaholics; (c) engaged workers.

\section{Individual antecedents}

We are in agreement with Snir and Harpaz (2012) in emphasizing that personal characteristics are responsible for fueling workaholism. However, we do not think that addiction to work is the only factor involved; we believe, instead, that addiction is an inherent component of workaholism (we defined it as the externalizing component in our definition), and that more than one factor is at work at the individual level (see Table 2 for a summary of the antecedents of workaholism).

In the literature there are many studies of the personal antecedents of workaholism. At a 
theoretical level, Szpitalak (2014) proposed that operant conditioning could be at work in determining the development of workaholism. According to Szpitalak (2014), workaholism occurs if it leads to some desired effects (or if the person is reinforced), such as material profit, social approval, high social status, avoidance of difficult relationships, and reduction of anxiety or tension. There are also many empirical studies that take into account various individual factors.

With regard to personality traits, there is evidence for a positive association between workaholism and conscientiousness (e.g., Aziz \& Tronzo, 2011; Guédon \& Bernaud, 2015), neuroticism (e.g., Andreassen, Griffiths, et al., 2014; Guédon \& Bernaud, 2015; Hameed, Amjad, \& Hameed, 2013), and openness to experience (e.g., Aziz \& Tronzo, 2011; Guédon \& Bernaud, 2015; Hameed et al., 2013). Moreover, a specific personality antecedent of workaholism related to obsessive-compulsive traits is perfectionism (e.g., Bovornusvakool et al., 2012; Falco, Piccirelli, Girardi, Di Sipio, \& De Carlo, 2014; Mazzetti, Schaufeli, \& Guglielmi, 2014; Stoeber et al., 2013; Tziner \& Tanami, 2013). However, personality traits are difficult to change; hence, we believe that future studies should address additional personal antecedents, such as emotions and their regulation, motivation, and cognitive biases. These three factors could be effectively targeted by preventive and treatment group interventions in the organizations.

With regard to emotion-related antecedents, Waghorn and Chant (2012) found that having a psychiatric disorder, in particular depression and anxiety disorders, is a risk factor for workaholism, similar to, more generally, experiencing negative affect (e.g., Clark, Michel, Stevens, Howell, \& Scruggs, 2013; van Wijhe, Peeters, \& Schaufeli, 2011, 2013; van Wijhe, Peeters, Schaufeli, \& van den Hout, 2011). This could be linked to a low ability to down-regulate negative emotions, which has been found to be correlated with workaholism
(Wojdylo, Baumann, Fischbach, \& Engeser, 2014). We speculate that this relationship can be explained by referring to both externalizing and internalizing disorders, which supports the usefulness of a conceptualization of workaholism including both addiction and obsessivecompulsive symptoms. Similar to the mood modification criteria for addictions, we propose that if a worker persistently experiences negative affect, he/she could try to change his/her mood by means of excessive working. This is also in line with the DSM-5 (APA, 2013) definition of a compulsion as a repetitive behavior (working, in this case) that the individual feels obliged to perform aiming to prevent or reduce anxiety or distress.

Motivation is another important individual antecedent of workaholism. Van Beek, Taris, Schaufeli, and Brenninkmeijer (2014) analyzed prevention-focused (i.e., aiming to satisfy the need for security) and promotion-focused (i.e., aiming to satisfy the need for growth and development) motivations in workers; they found that workaholism is positively associated with prevention-focused motivation, but also, albeit in a lesser extent, with having a promotion focus. They concluded that the motivational picture in workaholics is complex, characterized by divergent goals. In line with this complexity, two other types of work motivation positively predict workaholism as well, one controlled (introjected regulation; being motivated by internal rewards and punishment) and one autonomous (identified regulation; being motivated by the personal importance of work; Stoeber et al., 2013; van Beek, Hu, Schaufeli, Taris, \& Schreurs, 2012). More specifically, van den Broeck et al. (2011) showed that both autonomous and controlled motivation are positively associated with the excessive working component of workaholism, while only controlled motivation is positively associated with the compulsively working component. Interestingly, van Beek et al. (2011) found that workaholics are driven by controlled motivation, while engaged workaholics are driven by both controlled 
and autonomous motivations. These findings could explain why some of the studies that did not differentiate between disengaged and engaged workaholics (Stoeber et al., 2013; van Beek et al., 2012; van Beek et al., 2014) also found more diverse kinds of motivations in workaholics.

Much attention has been drawn on cognitive antecedents of workaholism as well. Some studies have shown the presence, in workaholics, of an "enough continuation" rule, that is continuing to work until one has "done enough" (van Wijhe, Peeters, \& Schaufeli, 2011, 2014; van Wijhe, Peeters, Schaufeli, \& van den Hout, 2011). Van Wijhe et al. (2014) also proposed the possible existence of a dynamic process involving this cognitive rule and workaholism, suggesting that these mutually reinforce each other. Other cognitive antecedents include performance-based self-esteem (van Wijhe et al., 2014) and, out of four irrational beliefs studied (performance demands, approval of coworkers, failure, control), performance demands are also relevant; these refer to perfectionism at work (van Wijhe et al., 2013). As far as coping styles are concerned, the obsessive work drive component of workaholism is related to passive avoidance and depressive reaction patterns (Andreassen, Hetland, \& Pallesen, 2012).

In summary, negative emotions could play an important role in the onset and maintenance of workaholism, since they may activate overworking as an attempt to cope with negative feelings. Moreover, we believe that motivation too could explain the maintenance of workaholism. The external kinds of motivation (e.g., controlled motivation) depend on external positive effects, such as money or social approval; hence, they foster a mechanism of positive reinforcement of workaholism (see Szpitalak, 2014). Following this consideration, we suggest that preventive interventions should favor intrinsic motivations in order to lessen the effects of external factors on the working behavior.
Finally, cognitive biases could play another important role in workaholism since they may lead to a form of information processing that could favor workaholism. However, it is also possible to change irrational beliefs to more adaptive ones. Indeed there are effective interventions for some psychological disorders (e.g., social anxiety disorder) that are based on cognitive bias modification; cognitive antecedents could thus be a proper target of interventions for workaholism as well; a more accurate understanding of the cognitive processes underlying workaholism could help in creating effective treatment and intervention programs.

Taken all together, these studies on individual antecedents lead to the following statement:

Proposition 4a: Some individual factors are worthy of intensive study, since they could have an important role in the onset and maintenance of workaholism and they are easier to change, compared to personality traits. These are potential antecedents related to emotion (i.e., inability to down-regulate negative emotions), motivation type (intrinsic vs. extrinsic), and cognitions (i.e., irrational beliefs or coping styles).

Proposition 4b: It is important to distinguish between disengaged workaholics and engaged workaholics when studying antecedents of workaholism, as there could be some differences in the relationships of potential antecedents to each of these forms of workaholism.

\section{Situational antecedents}

Along with individual antecedents, we believe that situational factors also have an important role in predicting workaholism. (See Table 2 for a list of workaholism antecedents.) It is important to study these factors, as they are easier to change than person-related antecedents, and they could thus also be proper targets for preventive interventions. 
Nevertheless, only a few studies have examined organizational factors in relation to workaholism. For example, job change could induce a variation in workaholism (Mäkikangas et al., 2013). In addition, Machado, Desrumaux, and Dose (2015) showed how psychological demands, overinvestment, and emotional dissonance could have central roles in predicting workaholism. Rezvani, Bouju, KerivenDessomme, Moret, and Grall-Bronnec (2014) found a correlation between high job demands and workaholism. However, Salanova et al. (2014) found that workaholics reported fewer job demands compared to relaxed workers, representing a more positive (or less impaired) profile than relaxed workers. This study supports our speculation that different profiles of workaholism might be affected differently by the same organizational factors, pointing out the importance of distinguishing between engaged and disengaged workaholics when studying risk factors.

In the area of situational antecedents, a valuable study is that of Mazzetti et al. (2014). They found that conscientiousness and selfefficacy are person-related characteristics associated with workaholism. However, they found this association only when the worker also perceived an overwork climate (which indicate the perception that the work environment is characterized by an expectation that they overwork, for example working in free time or doing unpaid overtime work), while achievement motivation and perfectionism both showed an interaction effect with environmental factors and a direct effect on workaholism. Thus, for the first time, they propose an interaction between individual characteristics and environmental factors instead of considering them separately. This interaction could be another reason (in addition to the difference between engaged and disengaged workaholics) for the different results related to some antecedent factors. We think that future studies should be aware of such interactions when studying individual and situational antecedents, also taking into account the presence or absence of a perceived overwork climate or other organizational antecedents. Therefore, another statement for our model is that:

Proposition 5: In studying workaholism antecedents, researchers should both differentiate between engaged and disengaged workaholics and study the interaction between individual and organizational factors.

In addition, we believe that, besides the importance of deepening the analysis of organizational factors, it will also be necessary to study family-related situational antecedents. We suspect that an overwork climate could exist not only in the work setting, but in the family too. We found only two studies that analyzed these aspects. Kravina, Falco, De Carlo, Andreassen, and Pallesen (2014) found that fathers' excessive work component of workaholism is positively related to their adult sons' and daughters' workaholism. Bakker, Shimazu, Demerouti, Shimada, and Kawakami (2014) found in contrast that there is not a correlation between one's own workaholism and that of one's partner. It would be interesting if future studies analyzed whether workaholics had been raised by hard-working parents. Studying whether the workaholic's partner is a workaholic too, or unemployed, would also be interesting, as both of these things, for different reasons, could fuel workaholism. Workaholic partners could promote a positive attitude toward hard work or press the spouse to work as hard as they do; however, it would also be possible that there is not a relationship such as that found by Bakker et al. (2014), perhaps because the workaholic partner might press the other to work less in order to manage family issues. In the case of an unemployed partner, we think that, instead, this partner would favor workaholism because he/she is not earning a salary, while the other partner would feel pressed to work more in order to earn more. Given these considerations, we propose that: 
Table 3. Comprehensive Model: Individual and organizational negative outcomes

\begin{tabular}{ll}
\hline Individual outcomes & Low wellbeing at work \\
& Health impairment \\
& Work-family conflict \\
& Low family well-being \\
Organizational outcomes & Low performance \\
& Aggressive behaviors \\
& Low organizational citizenship behaviors
\end{tabular}

Note. These negative outcomes are present at higher level in disengaged workaholics than in engaged workaholics.

Proposition 6: Workaholism is also due to situational factors, especially to an overwork climate that could be diffused at both work and home.

\section{Individual outcomes}

Many studies have analyzed the outcomes of workaholism. With regard to personal consequences, many studies have found that workaholism is associated with lower levels of well-being and more health impairment (e.g., Andreassen, Hetland, Molde, \& Pallesen, 2011; Avanzi, van Dick, Fraccaroli, \& Sarchielli, 2012; Falco et al., 2013; Guglielmi, Simbula, Schaufeli, \& Depolo, 2012; Shimazu, Schaufeli, Kamiyama, \& Kawakami, 2015; Simbula \& Guglielmi, 2013; Wojdylo et al., 2014). Concerning more specific outcomes, recent studies of workaholics found exhaustion (van den Broeck et al., 2011), lower levels of psychological detachment from work (Innanen et al., 2014; Shimazu, De Jonge, Kubota, \& Kawakami, 2014), a lower degree of relaxation (Innanen et al., 2014), higher psychological distress (Shimazu, Demerouti, Bakker, Shimada, \& Kawakami, 2011), higher levels of stress (Caesens, Stinglhamber, \& Luypaert, 2014), sleep problems (Andreassen et al., 2011; Caesens et al., 2014; Kubota, Shimazu, Kawakami, \& Takahashi, 2014), depressive mood (Matsudaira et al., 2013; Wojdylo, Baumann, Buczny, Owens, \& Kuhl, 2013), disabling back pain and absences due to illness, particularly due to mental health problems (Matsudaira et al.,
2013). Workaholism is also associated with work overload (Del Líbano, Llorens, Salanova, \& Schaufeli, 2012), lower job satisfaction (Caesens et al., 2014; Simbula \& Guglielmi, 2013; van Beek et al., 2014), decreased perception of equality (Simbula \& Guglielmi, 2013), and a lower sense that rewards are sufficient (Innanen et al., 2014). Many studies also highlighted the impact of workaholism on family functioning, referring to the work-family conflict (Clark et al., 2013; Del Líbano et al., 2012; Simbula \& Guglielmi, 2013). More specifically, some studies found a positive relationship between workaholism and work-to-family conflict (e.g., Andreassen, Hetland, \& Pallesen, 2013; Bakker et al., 2014; Shimazu et al., 2011). In addition, Shimazu et al. (2011) reported that the husbands of workaholic women are more likely to experience family-to-work conflict, while the wives of workaholic men are not. Thus, in this study, workaholism in women has a negative impact on both women's and their partners' family and work functioning. Finally, a recent study suggests fathers' excessive working component of workaholism is positively related to their working sons and daughters' workaholism (Kravina et al., 2014).

Taken together, these studies highlight the numerous negative consequences that affect the workaholics - who experience impairment in their health and work-to-family conflict-but that also have a negative impact on his/her relatives (see Table 3 for a list of the negative outcomes correlated with workaholism). From this, the following statement is derived: 
Proposition 7: Workaholism is correlated with negative personal consequences, such as physical and psychological health impairment and problems in family functioning.

\section{Situational outcomes}

There are many recent studies also relating to organizational outcomes. These point out that workaholism is associated with greater absence due to sickness (Falco et al., 2013), lower work performance (Falco et al., 2013; Gorgievski, Moriano, \& Bakker, 2014; Shimazu et al., 2015; van Beek et al., 2014), less organizational citizenship behavior (Birkeland \& Buch, 2015; Choi, 2013), aggressive workplace behavior (Balducci et al., 2012), and higher intention to change jobs (van Beek et al., 2014).

It is interesting to note, regarding these turnover intentions, that Choi (2013) found in contrast that workaholism is associated with a lower intention for job turnover. In addition, another study found a positive association of workaholism with innovative behavior (Gorgiesvski et al., 2014). These studies are in line with a recent theoretical proposal to consider workaholism as not necessarily a negative addiction, since it could have positive aspects for both the individual and the organization (Baruch, 2011). However, we think that the positive outcomes found in these studies could be explained by the lack of a distinction between the engaged and disengaged subtypes of workaholism. Hence, we reaffirm our idea that future studies should investigate not only antecedents but also consequences, examining separately the relationships of these variables to engaged and disengaged workaholism. We speculate that those studies finding positive organizational consequences were probably based on a higher proportion of engaged workaholics, while the others were based on a higher presence of disengaged workaholics. We have to note that none of the recent studies on personal consequences found positive effects of workaholism. However, the study of van Beek et al. (2011) also showed that engaged workaholics experience negative personal consequences compared to engaged employees, although at a lower level than for workaholic employees. Hence, we could hypothesize that the only expected differences between studies with more (or fewer) engaged workers would be relative to higher or lower levels of personal negative consequences. We conclude this section concerning situational outcomes (see Table 3 for the list of the negative outcomes correlated to workaholism) by stating that:

Proposition 8: Workaholism is associated with negative organizational outcomes, such as low performance, aggressive behavior, and low organizational citizenship behaviors.

Proposition 9: In studying workaholism outcomes, researchers should differentiate between engaged and disengaged workaholics. This could also help clarify the reasons why some studies have found positive consequences of workaholism for the organization.

\section{Intervention programs: Need for empirical studies on clinical and preventive interventions}

In the literature, many researchers have shown great interest for the definition, antecedents, and outcomes of workaholism. There is recognition of the wide prevalence of this phenomenon and its negative impact on the individual and his/her organization. Surprisingly, there has been no great interest in therapy and prevention.

Currently, suggested interventions concerning workaholism are all at a therapeutic level, and they have not been empirically validated. These include self-help groups, rational emotive behavioral therapy (RET; Ellis, 1977), cognitive behavioral therapy, relaxation training, stress management techniques, and assertiveness training (Giannini \& Scabia, 2014). In 
addition, recently there has been interest in mindfulness as a strategy to improve mental health, including in relation to workaholism, in employees (e.g., Hülsheger, Alberts, Feinholdt, \& Lang, 2013; Hülsheger, Feinholdt, \& Nübold, 2015; van Gordon, Shonin, Zangeneh, $\&$ Griffiths, 2014). However, there are only few studies on the efficacy of mindfulness as regards work-related health (e.g., Michel, Bosch, \& Rexroth, 2014; Shonin, van Gordon, $\&$ Griffiths, 2014). Thus, we conclude that the therapeutic programs suggested so far need to be validated regarding their efficacy.

Besides clinical interventions, we believe it would be even more important to develop and evaluate preventive programs too. One study that may represent a first step towards this goal is that of Mazzetti et al. (2014), which pointed out that it is worthwhile acting on organizational climate, since personality characteristics are generally stable and organizational factors interact with them in promoting workaholism. They proposed that managers should act as a model for their employees, demonstrating how to reach good results by means of adequate time management, a healthy work-life balance, and by avoiding working in their free time. A contribution to ideas for prevention programs also comes from some recent studies on leisure time. Bakker, Demerouti, Oerlemans, and Sonnentag (2013) found that practicing a sport or doing exercise are useful recovery strategies for workaholics. They therefore proposed that organizations should encourage employees not to work during leisure time, but to dedicate themselves to sport or exercise. De Bloom, Radstaak, and Geurts (2014) analyzed the effect of long vacations; they found that workaholics experience a great deal of improvement in emotional well-being but also a large decrease when they come back to work. Therefore, they conclude that a long vacation has a positive effect on workaholics, but that preventive interventions are necessary to avoid the large decline in affective well-being when they return to work.
Taking into account our previous statements as well, we suggest that the major areas to address in planning preventive interventions should be those that relate to workaholism antecedents that are easier to change. In the area of person-related antecedents, these are mainly irrational beliefs and cognitive biases, which could be modified to reduce workaholism within a group setting in the organization. In addition, we speculate that organizational antecedents are easier to change than both familial antecedents and personal ones. These are targetable in the organization itself and would aim to reduce overwork climate and favor holidays and sport in leisure time. We think that, in contrast, family-related antecedents will be more difficult to change, as they would require an intervention also involving relatives; this is more feasible in a clinical setting and more difficult to implement at work, as it requires the participation of the family. However, this does not mean that only organizational factors need major investigation; we think that indeed familial ones should also be studied, as currently they are both understudied.

Based on these considerations, we conclude with a proposition that is not testable, but that we believe is important to propose in order to point out the great need of workaholismspecific interventions:

Proposition 10: There is great need for the development of preventive interventions; these should especially target organizational antecedents, since these are easier to change than both family and individual antecedents.

\section{A proposal for DSM-like criteria}

Given all of the suggestions that we have proposed, we believe it may be useful to suggest diagnostic criteria for our definition of workaholism. We have not found any such proposal in the previous literature. We think that it would be valuable to have criteria to refer to when 
A. Persistent and recurrent problematic working behaviors leading to clinically significant impairment or distress, as indicated by the individual exhibiting six (or more) of the following in a 6-month period. Four of the symptoms must be (I) work-related obsessions, (2) work-related compulsions, (3) perfectionism, and (4) low work engagement:

I. Work-related obsessions, defined as recurrent and persistent thoughts related to work that in most individual cause marked anxiety or distress.

2. Work-related compulsions, defined as repetitive working behaviors (e.g., staying longer at work, working at home nearly all the evenings and weekends) that the individual feels driven to perform in response to his or her work-related obsessions.

3. Perfectionism (e.g. high standards in work, insecurity about own work).

4. Low levels of work engagement (e.g., work is not pleasurable; low level of energy while working).

5. Often works more than was intended.

6. There is a persistent desire or unsuccessful efforts to reduce the amount of time dedicated to work.

7. Recurrent work-related behaviors as described above resulting in a failure to fulfill major role obligations at home.

8. Continued work-related behaviors as described above despite having persistent or recurrent social or interpersonal problems caused or exacerbated by these behaviors themselves.

9. Important social, family, or recreational activities are given up, reduced or impaired because of workaholism.

10. Often overworks in order to reduce negative mood or feelings of distress.

II. Lies to conceal the extent of involvement in work.

12. Experiences withdrawal symptoms when not working or interrupted while working (e.g., is irritable, restless, bored).

B. These work-related symptoms are not attributable to the physiological effects of a substance (e.g., a drug of abuse, a medication) or another medical condition.

C. The disturbance is not better explained by the symptoms of another mental disorder (e.g., work-related compulsion is not a consequence of an obsession not work-related, which is typical of the obsessivecompulsive disorder; perfectionism and high involvement in work is not explainable by obsessivecompulsive personality disorder; work-related symptoms are not a consequence of fear of negative evaluation in the context of social anxiety disorder; overworking is not due to a manic episode).

Figure I. Proposal for disengaged workaholism DSM-like criteria.

studying workaholism, as this could help to share a consistent definition of it, leading to cumulative knowledge on the construct, something which is currently lacking despite the extensive literature on workaholism. As an implication, this could also help clarify some of the current ambiguous findings and thus favor the possible recognition of workaholism as a diagnostic category for the next edition of the DSM. Indeed, in order to classify a disorder in the DSM, there is need for adequate peerreviewed evidence supporting the diagnostic criteria and the description of the course of the problem behavior.
For these reasons, we proposed DSM-like criteria for the diagnosis of workaholism (see Figure 1). We created these criteria by referring to three DSM-5 (APA, 2013) diagnoses: for Criteria 1 and 2 (work-related obsessions and compulsions), we made reference to obsessive-compulsive disorder (internalizing disorder), while for Criteria 5 to 12 (addiction symptoms) we referred to substance use disorders and gambling disorder (externalizing disorders). In addition, we added Criterion 3 with reference to studies highlighting the importance of perfectionism in workaholism, and Criterion 4 (low levels of work 
engagement) referring to our three-factor conceptualization of workaholism.

More specifically, in Criterion A, we affirm that in order to make a clinical diagnosis of workaholism, there should be evidence of persistent and recurrent problematic working behaviors leading to clinically significant impairment or distress, as indicated by the presence of six (or more) of the 12 symptoms proposed. Moreover, these symptoms should last at least 6 months. We selected six criteria as the cut-off because, for substance use disorders, two criteria (out of 11) are required, while for gambling addiction four criteria (out of nine) are needed. Since we also specified that four criteria must be met for the diagnosis (i.e., work-related obsessions, work-related compulsions, perfectionism, and low work engagement), we thought that requiring at least two of the eight addiction criteria (in line with the substance use disorders) would be sufficient to make the diagnosis. With regard to the duration, we chose 6 months in relation to the duration required by the diagnoses we referred to: 12 months for the addictive disorders and no duration requirement in obsessive-compulsive disorder (APA, 2013).

Thus, we suggest requiring the presence of the following four symptoms for a workaholism diagnosis: (1) work-related obsessions, which are recurrent and persistent thoughts related to work generally associated to anxiety or distress; (2) work-related compulsions, which are repetitive working behaviors, such as working at home nearly all evenings and weekends, which the individual feels driven to perform in response to his/her work-related obsessions; (3) perfectionism (e.g., high standards in work, insecurity about one's own work); and (4) low levels of work engagement (e.g., work is not pleasurable, low levels of energy while working).

In addition, there would also need to be two of the following eight addiction symptoms: (a) the individual often works more than was intended; (b) he/she persistently desires or makes unsuccessful efforts to reduce the amount of time dedicated to work; (c) overworking results in a failure to fulfill major role obligations at home (e.g., participation in the care of children); (d) workaholism continues despite persistent or recurrent social or interpersonal problems caused or exacerbated by workaholism itself; (e) important social, family, or recreational activities are given up, reduced, or impaired because of workaholism; (f) the individual often overworks in order to reduce negative mood or feelings of distress; ( $g$ ) the worker lies to conceal the real extent of involvement in work; (h) the individual experiences withdrawal symptoms when not working or when interrupted while working (e.g., is irritable, bored).

Moreover, we specify in Criterion B that workaholism symptoms should not be attributable to the physiological effects of a substance (e.g., a drug of abuse, a medication) or another medical condition. This is a criterion generally required for diagnoses in the DSM. Finally, in Criterion $\mathrm{C}$, we note some of the other mental disorders that could better explain workaholism, such as social anxiety disorder, a manic episode, or obsessive-compulsive personality; in these cases, a diagnosis of workaholism should not be made. With regard to obsessivecompulsive personality disorder, we would like to point out that we think that this is an important specification, as there could be highly perfectionist persons whose overworking is a consequence of their high perfectionism. In this case, clinical intervention should not be for workaholism, but rather for the disorder which causes overworking as one of its many consequences.

In conclusion, we propose that if our model were to be confirmed by future studies, workaholism should be placed in the DSM between the chapters on obsessive-compulsive and related disorders and substance-related and addictive disorders, since we have theorized that workaholism is characterized by aspects of both disorders. Our proposal is in line with the new organization of disorders in the DSM-5, 
which puts similar diagnoses close to each other. For example, the chapter "ObsessiveCompulsive and Related Disorders" follows the one on anxiety disorders (which in the previous edition also included obsessivecompulsive disorder); the next chapter covers trauma and stressor-related disorders, placed there because it shares some features with the two previous chapters but also with the immediately following one on dissociative disorders. Keeping in mind DSM-5's (APA, 2013) organization, we also propose that the text on workaholism should give some consideration to the possible differences in overworking across different cultures (another point deserving major study) and to the fact that overworking behaviors should be judged by the clinician based on the sociocultural context of the individual. In different countries there are indeed different cultures related to work, as well as different laws for the number of hours the employee is allowed to work.

It is important to note that our DSM-like classification proposal aims to better define the workers who could benefit from a clinical diagnosis of workaholism. Indeed, our main aim is not overpathologizing a common behavior such as work (given the risk for stigmatization within organizations). We believe that having some diagnostic criteria to refer to could help decrease the number of workers labeled as workaholics (e.g., avoiding making a diagnosis of workaholism for engaged workaholics or engaged workers). In this way an organizational culture could be favored that aims to prevent workaholism in all workers, instead of advising an employee to seek individual treatment.

\section{Conclusions}

From the analysis of workaholism literature, we concluded that while there have been numerous studies of this construct, a shared definition of it is still lacking, hence preventing the cumulative growth of knowledge. Therefore, we developed a comprehensive and easily testable theoretical model. We call it a "comprehensive model," as we think that it includes all the major components of workaholism; however, we do not exclude the possibility that there could be also other comprehensive models.

We believe that we have improved the conceptualization of workaholism by taking into account both an internalizing and externalizing perspective, so as to promote its study without using an a priori addiction-related theoretical framework and hence highlighting its real characteristics (see Kardafelt-Winther, 2015).

In summary, we define workaholism as a clinical condition that is characterized by both externalizing (i.e., addiction) and internalizing (i.e., obsessive-compulsive) symptoms, and by low levels of work engagement, from which arises the distinction between disengaged and engaged workaholics. We point out that this distinction between engaged and disengaged workaholics is a very important one, since it could prevent overpathologizing a common behavior such as work (see Billieux et al., 2015). However, we also propose that engaged workaholics too should receive preventive interventions in order to support the presence of or an increase in engaged workers in organizations. These are indeed the most positive kind of the three types of heavy work investors, since, although engaged workaholics are characterized by less negative outcomes for themselves and their organizations compared to disengaged workaholics, this occurs to a lesser extent than for engaged workers.

We also propose some individual and situational antecedents (e.g., cognitive biases, overwork climate) and negative outcomes (e.g., family functioning problems, low work performance) of workaholism. Concerning workaholism's outcomes, a few studies also have reported some associated positive outcomes for the organizations, such as lower turnover intentions (Choi, 2013) and innovative behavior (Gorgievski et al., 2014). We note that future studies should be cautious in 
emphasizing these potential positive effects so as to avoid promoting an organizational climate of overwork, which could increase employees' risk of developing workaholism. Moreover, in line with the study of Mazzetti et al. (2014), we suggest that future studies should also analyze the interaction between organizational and personal antecedents to highlight which individual antecedents have a direct effect on workaholism and which instead have an indirect effect moderated by organizational climate. This knowledge could inform preventive and clinical interventions, as it would allow the differentiation of factors which need to be addressed in a therapeutic setting (personal antecedents with a direct influence) and the ones that can be changed at the organizational level (to avoid the activation of individual factors). In addition, we suggest distinguishing between disengaged workaholics, engaged workaholics, and engaged workers, when studying both the antecedents and the outcomes of workaholism. We believe it will be useful to understand that an organization could obtain the same positive outcomes from a disengaged and an engaged type of workaholic, as well as from an engaged worker. This could lead organizations to favor work engagement, or at least avoid disengaged workaholism, which could have positive consequences for both the employer and the worker, as it could improve positive aspects and avoid negative outcomes of workaholism.

Finally, regarding clinical and preventive interventions, we suggest that the major areas to be addressed by preventive interventions should be those relating to the antecedents that are easier to change. More specifically, we propose that cognitive biases and overworking climate at work deserve more research, since they are both targetable in the organization itself and in a group setting. We conclude by proposing a research agenda that we hope will guide future research: (a) to create a comprehensive workaholism test (we have already submitted it for publication) allowing the measurement and classification of the following four types of workers: detached workers, engaged workers, engaged workaholics, disengaged workaholics; (b) to reanalyze the widely studied antecedents and outcomes of workaholism with reference to the previous four clusters of workers, while simultaneously analyzing the interaction between personal and situational antecedents; (c) to deepen the analysis of overwork climate, both in the organization and in the family; (d) to extend the analysis of cognitive factors which could be antecedents of workaholism and appropriate targets of intervention; (e) to propose and test clinical and preventive interventions specifically for workaholism; (f) to consider our comprehensive model as an evolving framework which needs to be tested in all its parts in order to determine empirically which relationships are necessary, which have to be deleted, and, finally, if new relationships should be added to the model; $(\mathrm{g})$ to test by means of both quantitative and qualitative methods whether our DSM-like workaholism criteria could be useful or if they need to be changed.

\section{Acknowledgements}

We thank Prof. David Schuldberg for discussions and his help in the English proofreading and editing of the manuscript and Prof. Ramón Rico for reading the first version of the manuscript and giving us valuable comments to improve it.

\section{Declaration of Conflicting Interests}

The author(s) declared no potential conflicts of interest with respect to the research, authorship, and/or publication of this article.

\section{Funding}

The author(s) received no financial support for the research, authorship, and/or publication of this article.

\section{References}

American Psychiatric Association (APA). (2013). DSM-5: Diagnostic and statistical manual of 
mental disorders (5th ed.). Washington, DC: Author.

Andreassen, C. S. (2014). Workaholism: An overview and current status of the research. Journal of Behavioural Addictions, 3(1), 1-11.

Andreassen, C. S., Griffiths, M. D., Hetland, J., Kravina, L., Jensen, F., \& Pallesen, S. (2014). The prevalence of workaholism: A survey study in a nationally representative sample of Norwegian employees. PLoS One, 9(8), 1-10.

Andreassen, C. S., Griffiths, M. D., Hetland, J., \& Pallesen, S. (2012). Development of a work addiction scale. Scandinavian Journal of Psychology, 53, 265-272.

Andreassen, C. S., Hetland, J., Molde, H., \& Pallesen, S. (2011). "Workaholism" and potential outcomes in well-being and health in a cross-occupational sample. Stress and Health, 27, 209-214.

Andreassen, C. S., Hetland, J., \& Pallesen, S. (2012). Coping and workaholism. Results from a large cross-occupational sample. TPM: Testing, Psychometrics, Methodology in Applied Psychology, 19(4), 281-290.

Andreassen, C. S., Hetland, J., \& Pallesen, S. (2013). Workaholism and work-family spillover in a crossoccupational sample. European Journal of Work and Organizational Psychology, 22(1), 78-87.

Andreassen, C. S., Hetland, J., \& Pallesen, S. (2014). Psychometric assessment of workaholism measures. Journal of Managerial Psychology, 29(1), 7-24.

Andreassen, C. S., Ursin, H., Eriksen, H. R., \& Pallesen, S. (2012). The relationship of narcissism with workaholism, work engagement, and professional position. Social Behavior and Personality, 40(6), 881-890.

Astakhova, M., \& Hogue, M. (2014). A heavy work investment typology: A biopsychosocial framework. Journal of Managerial Psychology, 29(1), 81-99.

Avanzi, L., van Dick, R., Fraccaroli, F., \& Sarchielli, G. (2012). The downside of organizational identification: Relations between identification, workaholism and well being. Work \& Stress, 26(3), 589-307.

Aziz, S., \& Tronzo, C. L. (2011). Exploring the relationship between workaholism facets and personality traits: A replication in American workers. The Psychological Record, 61, 269-286.

Aziz, S., \& Zickar, M. J. (2006). A cluster analysis investigation of workaholism as a syndrome. Journal of Occupational Health Psychology, 11, 52-62.

Bakker, A. B., Demerouti, E., Oerlemans, W., \& Sonnentag, S. (2013). Workaholism and daily recovery: A day reconstruction study of leisure activities. Journal of Organizational Behavior, 34, 87-107.

Bakker, A. B., Schaufeli, W. B., Leiter, M. P., \& Taris, T. W. (2008). Work engagement: An emerging concept in occupational health psychology. Work and Stress, 22(3), 187-200.

Bakker, A. B., Shimazu, A., Demerouti, E., Shimada, K., \& Kawakami, N. (2014). Work engagement versus workaholism: A test of the spillovercrossover model. Journal of Managerial Psychology, 29(1), 63-80.

Balducci, C., Cecchin, M., Fraccaroli, F., \& Schaufeli, W. B. (2012). Exploring the relationship between workaholism and workplace aggressive behaviour: The role of job related emotion. Personality and Individual Differences, 53, 629-634.

Baruch, Y. (2011). The positive wellbeing aspects of workaholism in cross cultural perspective: The chocoholism metaphor. Career Development International, 16(6), 572-591.

Billieux, J., Schimmenti, A., Khazaal, Y., Maurage, P., \& Heernen, A. (2015). Are we overpathologizing everyday life? A tenable blueprint for behavioral addiction research. Journal of Behavioral Addictions, 4(3), 119-123.

Birkeland, I. K., \& Buch, R. (2015). The dualistic model of passion for work: Discriminative and predictive validity with work engagement and workaholism. Motivation and Emotion, 39, 392-408.

Bovornusvakool, W., Vodanovich, S. J., Ariyabuddhiphongs, K., \& Ngamake, S. T. (2012). Examining the antecedents and consequences of workaholism. The Psychologist Manager Journal, 15(1), 56-70.

Caesens, G., Stinglhamber, F., \& Luypaert, G. (2014). The impact of work engagement and workaholism on well-being. Career Development International, 19(7), 813-835. 
Choi, Y. (2013). The differences between work engagement and workaholism, and organizational outcomes: An integrative model. Social Behavior and Personality, 41(10), 1655-1666.

Clark, M. A., Michel, J. S., Stevens, G. W., Howell, J. W., \& Scruggs, R. S. (2013). Workaholism, work engagement and work-home outcomes: Exploring the mediating role of positive and negative emotions. Stress and Health, 30, 287-300.

Clark, M. A., Michel, J. S., Zhdanova, L., Pui, S. Y., \& Baltes, B. B. (2016). All work and no play? A meta-analytic examination of the correlates and outcomes of workaholism. Journal of Management, 42(7), 1836-1873.

De Bloom, J., Radstaak, M., \& Geurts, S. (2014). Vacation effects on behaviour, cognition and emotions of compulsive and non-compulsive workers: Do obsessive workers go "cold turkey"? Stress and Health, 30, 232-243.

Del Líbano, M., Llorens, S., Salanova, M., \& Schaufeli, W. B. (2012). About the dark and bright sides of selfefficacy: Workaholism and work engagement. The Spanish Journal of Psychology, 15(2), 688-701.

Ellis, A. (1977). The basic clinical theory of rationalemotive therapy. In A. Ellis \& R. Grieger (Eds.), Handbook of rational-emotive therapy (pp. 3-34). New York, NY: Springer.

Falco, A., Girardi, D., Kravina, L., Trifiletti, E., Bartolucci, G. B., Capozza, D., \& De Carlo, N. A. (2013). The mediating role of psychophysic strain in the relationship between workaholism, job performance, and sickness absence: A longitudinal study. Journal of Occupational and Environmental Medicine, 55(11), 1255-1261.

Falco, A., Piccirelli, A., Girardi, D., Di Sipio, A., \& De Carlo, N. A. (2014). "The best or nothing": The mediating role of workaholism in the relationship between perfectionism and burnout. TPM: Testing, Psychometrics, Methodology in Applied Psychology, 21(2), 213-232.

Fassel, D. (1990). Working ourselves to death: The high cost of workaholism, the rewards of recovery. San Francisco, CA: HarperCollins.

Giannini, M., \& Scabia, A. (2014). Workaholism: An addiction or a quality to be appreciated? Journal of Addiction Research and Therapy, 5(3), 1-9.
Gorgievski, M. J., Moriano, J. A., \& Bakker, A. B. (2014). Relating work engagement and workaholism to entrepreneurial performance. Journal of Managerial Psychology, 29(2), 106-121.

Grebot, E. (2013). Réflexions sur la notion de workaholisme: Pour une approche transactionnelle. Annales Médico-Psychologiques, 171, 95-99.

Griffiths, M. D., \& Karanika-Murray, M. (2012). Contextualizing over-engagement in work: Towards a more global understanding of workaholism as an addiction. Journal of Behavioural Addictions, 1(3), 87-95.

Guédon, D., \& Bernaud, J.-L. (2015). Le workaholism danse une université française: Une perspective transactionelle. Pratiques Psychologiques, $21,71-85$.

Guglielmi, D., Simbula, S., Schaufeli, W. B., \& Depolo, M. (2012). Self-efficacy and workaholism as initiators of the job demands-resources model. Career Development International, 17(4), 375-389.

Hameed, F., Amjad, S., \& Hameed, A., (2013). The relationship between workaholism and personality. Middle East Journal of Scientific Research, 17(7), 898-907.

Hülsheger, U. R., Alberts, H., Feinholdt, A., \& Lang, J. W. B. (2013). Benefits of mindfulness at work: The role of mindfulness in emotion regulation, emotional exhaustion, and job satisfaction. Journal of Applied Psychology, 98(2), 310-325.

Hülsheger, U. R., Feinholdt, A., \& Nübold, A. (2015). A low-dose mindfulness intervention and recovery from work: Effects on psychological detachment, sleep quality, and sleep duration. Journal of Occupational and Organizational Psychology, 88(3), 464-489.

Innanen, H., Tolvanen, A., \& Salmela-Aro, K. (2014). Burnout, work engagement and workaholism among highly educated employees: Profiles, antecedents and outcomes. Burnout Research, 1, 38-49.

Kardefelt-Winther, D. (2015). Commentary on: Are we overpathologizing everyday life? A tenable blueprint for behavioral addiction research. Problems with atheoretical and confirmatory research approaches in the study of behavioral addictions. Journal of Behavioral Addictions, 4(3), 126-129. 
Kravina, L., Falco, A., De Carlo, N. A., Andreassen, C. S., \& Pallesen, S. (2014). Workaholism and work engagement in the family: The relationship between parents and children as risk factor. European Journal of Work and Organizational Psychology, 23(6), 875-883.

Kubota, K., Shimazu, A., Kawakami, N., \& Takahashi, M. (2014). Workaholism and sleep quality among Japanese employees: A prospective cohort study. International Journal of Behavioral Medicine, 21(1), 66-76.

Lazarus, R. S., \& Folkman, S. (1984). Stress, appraisal and coping. New York, NY: Springer.

Loscalzo, Y., \& Giannini, M. (2015). Workaholism: Cosa c'è di nuovo? [Workaholism: What's new?]. Counseling, 8(3).

Machado, T., Desrumaux, P., \& Dose, E. (2015). L'addiction au travail: Quels effets de la charge de travail, de la dissonance émotionnelle et du surinvestissement? Pratiques Psychologiques, 21, 105-120.

Machlowitz, M. (1980). Workaholics: Living with them, working with them. Reading, MA: Addison-Wesley.

Mäkikangas, A., Schaufeli, W., Tolvanen, A., \& Feldt, T. (2013). Engaged managers are not workaholics: Evidence from a longitudinal person-centered analysis. Journal of Work and Organizational Psychology, 29, 135-143.

Malinowska, D., \& Tokarz, A. (2014). The structure of workaholism and types of workaholic. Polish Psychological Bulletin, 45(2), 211-222.

Matsudaira, K., Shimazu, A., Fujii, T., Kubota, K., Sawada, T., Kikuchi, N., \& Takahashi, M. (2013). Workaholism as a risk factor for depressive mood, disabling back pain, and sickness absence. PLoS One, 8(9), 1-8.

Mazzetti, G., Schaufeli, W. B., \& Guglielmi, D. (2014). Are workaholics born or made? Relations of workaholism with person characteristics and overwork climate. International Journal of Stress Management, 23(1), 227-254.

Michel, A., Bosch, C., \& Rexroth, M. (2014). Mindfulness as a cognitive-emotional segmentation strategy: An intervention promoting work-life balance. Journal of Occupational and Organizational Psychology, 87(4), 733-754.
Mosier, S. K. (1983). Workaholics: An analysis of their stress success and priorities (Unpublished master's thesis). University of Texas at Austin.

Mudrack, P. E., \& Naughton, T. J. (2001). The assessment of workaholism as behavioral tendencies: Scale development and preliminary empirical testing. International Journal of Stress Management, 8, 93-111.

Ng, T. W. H., Sorensen, K. L., \& Feldman, D. C. (2007). Dimensions, antecedents, and consequences of workaholism: A conceptual integration and extension. Journal of Organizational Behavior, 28, 111-136.

Oates, W. (1971). Confessions of a workaholic: The facts about work addiction. New York, NY: World Publishing Company.

Patel, A. S., Bowler, M. C., Bowler, J. L., \& Methe, S. A. (2012). A meta-analysis of workaholism. International Journal of Business and Management, 7(11), 2-17.

Pencavel, J. (2014). The productivity of working hours. The Economic Journal, 125, 2052-2076.

Porter, G. (1996). Organizational impact of workaholism: Suggestions for researching the negative outcomes of excessive work. Journal of Occupational Health Psychology, 1, 70-84.

Rezvani, A., Bouju, G., Keriven-Dessomme, B., Moret, L., \& Grall-Bronnec, M. (2014). Workaholism: Are physicians at risk? Occupational Medicine, 64, 410-416.

Robinson, B. E. (1989). Workaholism: Hidden legacies of adult children. Deerfield Beach, FL: Health Communications.

Robinson, B. E. (1998). Chained to the desk: A guidebook for workaholics, their partners and children and the clinicians who treat them. New York, NY: New York University Press.

Salanova, M., Del Líbano, M., Llorens, S., \& Schaufeli, W. B. (2014). Engaged, workaholic, burnedout or just 9-to-5? Toward a typology of employee well-being. Stress and Health, 30, 71-81.

Schaufeli, W. B., Shimazu, A., \& Taris, T. W. (2009). Being driven to work excessively hard. The evaluation of a two-factor measure of workaholism in the Netherlands and Japan. CrossCultural Research, 43, 320-348. 
Schaufeli, W. B., Taris, T. W., \& van Rhenen, W. (2008). Workaholism, burnout, and work engagement: Three of a kind or three different kinds of employee well-being? Applied Psychology, 57, 173-203.

Scott, K. S., Moore, K. S., \& Miceli, M. P. (1997). An exploration of the meaning and consequences of workaholism. Human Relations, 50, 287-314.

Sharma, J., \& Sharma, P. (2011). Workaholism and its correlates: A study of academicians. International Journal of Management and Business Research, 1(3), 151-160.

Shimazu, A., De Jonge, J., Kubota, K., \& Kawakami, N. (2014). Psychological detachment from work during off-job time: Predictive role of work and non-work factors in Japanese employees. Industrial Health, 52, 141-146.

Shimazu, A., Demerouti, E., Bakker, A. B., Shimada, K., \& Kawakami, N. (2011). Workaholism and well-being among Japanese dual-earner couples: A spillover-crossover perspective. Social Science \& Medicine, 73, 399-409.

Shimazu, A., Schaufeli, W. B., Kamiyama, K., \& Kawakami, N. (2015). Workaholism vs. work engagement: The two different predictors of future well-being and performance. International Journal of Behavioral Medicine, 22(1), 18-23.

Shonin, E., van Gordon, W., \& Griffiths, M. D. (2014). The treatment of workaholism with meditation awareness training: A case study. Explore, 10(3), 193-195.

Simbula, S., \& Guglielmi, D. (2013). Engaged sì, workaholic no: Il ruolo di engagement e workaholism sulla salute e il benessere dei dirigenti scolastici. Giornale Italiano di Psicologia, 40(1), 195-207.

Snir, R., \& Harpaz, I. (2012). Beyond workaholism: Towards a general model of heavy work investment. Human Resource Management Review, 22, 232-243.

Sommers-Flanagan, J., \& Sommers-Flanagan, R. (2004). Counseling and psychotherapy theories in context and practice. Hoboken, NJ: John Wiley $\&$ Sons.

Spence, J. T., \& Robbins, A. S. (1992). Workaholism: Definition, measurement, and preliminary results. Journal of Personality Assessment, 58, 160-178.

Stoeber, J., Davis, C. R., \& Townley, J. (2013). Perfectionism and workaholism in employees: The role of work. Personality and Individual Differences, 55, 733-738.

Sussman, S. (2012). Workaholism: A review. Journal of Addiction Research and Theory, 6(1), 4120.

Sussman, S., Lisha, N., \& Griffiths, M. (2011). Prevalence of the addictions: A problem of the majority or the minority? Evaluation \& the Health Professions, 34(1), 3-56.

Szpitalak, M. (2014). Behavioral approach to workaholism. Postepy Psychiatrii I Neurologii, 23, 82-89.

Tziner, A., \& Tanami, M. (2013). Examining the links between attachment, perfectionism, and job motivation potential with job engagement and workaholism. Journal of Work and Organizational Psychology, 29, 65-74.

Van Beek, I., Hu, Q., Schaufeli, W. B., Taris, T. W., \& Schreurs, B. H. J. (2012). For fun, love, or money: What drives workaholic, engaged, and burned-out employees at work? Applied Psychology: An International Review, 61(1), 30-55.

Van Beek, I., Taris, T. W., \& Schaufeli, W. B. (2011). Workaholic and work engaged employees: Dead ringers or worlds apart? Journal of Occupational Health Psychology, 16(4), 468-482.

Van Beek, I., Taris, T. W., Schaufeli, W. B., \& Brenninkmeijer, V. (2014). Heavy work investment: Its motivational make-up and outcomes. Journal of Managerial Psychology, 29(1), 46-62.

Van den Broeck, A., Schreurs, B., De Witte, H., Vansteenkiste, M., Germeys, F., \& Schaufeli, W. (2011). Understanding workaholics' motivations: A self-determination perspective. Applied Psychology: An International Review, 60(4), 600-621.

Van Gordon, W., Shonin, E., Zangeneh, M., \& Griffiths, M. D. (2014). Work-related mental health and job performance: Can mindfulness help? International Journal of Mental Health Addiction, 12, 129-137. 
Van Wijhe, C. I., Peeters, M. C. W., \& Schaufeli, W. B. (2011). To stop or not to stop, that's the question: About persistence and mood of workaholics and work engaged employees. International Journal of Behavioral Medicine, 18, 361-372.

Van Wijhe, C. I., Peeters, M. C. W., \& Schaufeli, W. B. (2013). Irrational belief at work and their implications for workaholism. Journal of Occupational Rehabilitation, 23, 336-346.

Van Wijhe, C. I., Peeters, M. C. W., \& Schaufeli, W. B. (2014). Enough is enough: Cognitive antecedents of workaholism and its aftermath. Human Resource Management, 53(1), 157-177.

Van Wijhe, C. I., Peeters, M. C. W., Schaufeli, W. B., \& van den Hout, M. (2011). Understanding workaholism and work engagement: The role of mood and stop rules. Career Development International, 16(3), 254-270.

Villella, C., Martinotti, G., Di Nicola, M., Cassano, M., La Torre, G., Gliubizzi, M. D., Messeri, I., Petruccelli, F., Bria, P., Janiri, L., ... Conte, L. (2011). Behavioural addiction in adolescents and young adults: Results from a prevalence study. Journal of Gambling Studies, 27, 203-214.

Waghorn, G., \& Chant, D. (2012). Overworking among people with psychiatric disorders: Results from a large community survey. Journal of Occupational Rehabilitation, 22, 252-261.
Wojdylo, K., Baumann, N., Buczny, J., Owens, G., \& Kuhl, J. (2013). Work craving: A conceptualization and measurement. Basic and Applied Psychology, 35, 547-568.

Wojdylo, K., Baumann, N., Fischbach, L., \& Engeser, S. (2014). Live to work or love to work: Work craving and work engagement. PLoS One, 9(10), $1-7$.

World Health Organization (WHO). (1992). ICD-10 classifications of mental and behavioural disorder: Clinical descriptions and diagnostic guidelines. Geneva, Switzerland: Author.

\section{Author biographies}

Yura Loscalzo is a doctoral student in clinical psychology at the University of Florence. Her main areas of research are workaholism, studyholism (a construct she created during her $\mathrm{PhD}$ studies), and student wellbeing.

Marco Giannini is a researcher in clinical psychology at the University of Florence where he currently teaches Models of Psychotherapy and Clinical Psychology for health professions. His main areas of research are workaholism, studyholism, and psychotherapy. 